\title{
INFLUENCE OF PLATELET RICH FIBRIN ON OSSEOINTEGRATION OF IMMEDIATE PLACED ROOT ANALOGUE ZIRCONIA DENTAL IMPLANT
}

\author{
Khalid. M. El-Sayed* and Hussein Abdel Motelep Khalil**
}

\begin{abstract}
Purpose: This study investigated the effect of platelet rich fibrin (PRF) on zirconia root analogue dental implant osseointegration by histological analysis.

Material and method: Ten adult male mongrel dogs with split mandible technique were used. Left side of the mandible received only the implant and used as a control (group1). The right side received PRF and the implant (group2). Animals were sacrificed at 1 and 3 months. The specimens were prepared routinely and stained with $(\mathrm{H} \& \mathrm{E})$ stain for tissue details, and alizarin red stain for tissue mineralization.
\end{abstract}

Results: Image analysis of the slides for both groups showed a statistically higher mean bone formation in PRF group than control /time.

Conclusion: PRF appears to enhance osseointegration of root analogue zirconia dental implant.

\section{INTRODUCTION}

Immediate placed root analogue zirconia dental implant has recently been reintroduced by many researchers ${ }^{[1]}$. However, little information is available on enhancing osseointegration for such approach. The development of bioactive surgical additives, to regulate the inflammation and increase the speed of healing process ${ }^{[2]}$, is challenging as healing is a complex process, ${ }^{[3]}$. but it is known that platelets play an important role in both hemostasis and wound healing processes ${ }^{[4]}$.
Platelets' regenerative potential was introduced in the 70's ${ }^{[5]}$, when it was observed that they contain growth factors that are responsible for increase collagen production, cell mitosis, blood vessels growth, migration of other cells to the site of injury, and induction of cell differentiation. Platelet concentrates, platelet-rich plasma (PRP) and platelet-rich fibrin (PRF) act as bioactive surgical additives ${ }^{[6]}$.

Whitman et al ${ }^{[7]}$, in 1997 , were the first to use (PRP) in oral surgical procedures, reporting great

\footnotetext{
* Professor Department of Oral \& Maxillofacial Surgery, Faculty of Dental Medicine, Al-Azhar University, Cairo, Egypt.

* PhD Oral \& Maxillofacial Surgery, Consultant and Head of Department of Maxillofacial Surgery Nasser General Hospital.
} 
advantages as it enhances osteoprogenitor cells in the host and graft bone. However, using PRP is risky because bovine thrombin, which is used to handle PRP, may generate antibodies to factors V, $\mathrm{XI}$, and thrombin that could cause coagulopathies and may endanger life ${ }^{[6]}$.

On the other hand, PRF was firstly used in 2001 by Choukroun et al. ${ }^{[8]}$, specifically in oral and maxillofacial surgery. It consists of a matrix of autologous fibrin ${ }^{[2]}$ and has several advantages over PRP, including easier preparation and not requiring chemical manipulation of the blood, which makes it strictly an autologous preparation ${ }^{[6]}$.

Implant stability plays a major role in the success of osseointegration. Primary implant stability at placement is a mechanical phenomenon that is related to the local bone quality and quantity, the type of implant and placement technique used. Secondary implant stability is the increase in stability attributable to bone formation and remodeling at the implant/tissue interface and in the surrounding bone (osseointegration) ${ }^{[9]}$. The purpose of this study was to investigate the effect of PRF on zirconia root analogue dental implants osseointegration (histological analysis).

\section{MATERIAL AND METHODS}

This Split mouth, controlled study complies with all local laws set by the animal ethics committee of Cairo University. Ten adult male mongrel dogs were used in this study. Atropine sulfate ${ }^{\circledR}$ was injected subcutaneously 10-30 minutes before the surgery in a dose of $0.05 \mathrm{mg} / \mathrm{kg}$ body weight.

Animals were anesthetized: Anesthesia were Induced by a mixture of Xylazine-Hcl ${ }^{\circledR}(1 \mathrm{mg} / \mathrm{kg}$ body weight) and ketamine $\mathrm{Hcl} \circledast(5 \mathrm{mg} / \mathrm{kg}$ body weight) via a $23 \mathrm{~g}$ intravenous cannula through the cephalic vein. Anesthesia was maintained through the operation time by venous drip $(500 \mathrm{mg}$ thiopental sodium $/ 500 \mathrm{ml}$ dextrose $5 \%$ ) with drip rate of (28$40 \mathrm{drop} /$ minute). The respiratory airway was kept patent by applying an endotracheal tube.
The second lower premolar tooth was divided vertically in order to separate the two roots followed by gentle extraction of the mesial root.

The tooth was 3D laser scanned. The macroretentive means were designed on the interdentally spaces to aid in primary stability and the crown stump was reduced for freeing the occlusion. By using the CAD CAM machine, the implant was milled from a zirconium dioxide yttria stabilized block. The implant surface was roughened by sandblasting.

$\boldsymbol{P R F}$ : A blood sample is taken without anticoagulant in $10-\mathrm{mL}$ glass tube ${ }^{[2]}$, then immediately centrifuged at $3,000 \mathrm{rpm}$ for 10 minutes ${ }^{[2,4]}$. The resultant product consists of the following three layers [2]: Top layer consisting of a cellular plasma, PRF clot in the middle and Red corpuscle base at the bottom. Then the PRF clot was separated and put in a sterile cup for approximately 10 minutes to allow the release of the proper serum contained within ${ }^{[2]}$.

Left side of the mandible received only the implant and used as a control (group 1). The right side, received PRF and the implant (group 2).

Histo-pathological Investigations: The specimens were prepared routinely and stained with (H\&E) stain for tissue details, and alizarin red stain for tissue mineralization. For alizarin red stain, image analysis of five sequenced slides for both groups were analyzed at 1 and 3 months using a Photoshop 7 software program on the home laptop. After taking a photograph for tissue sections at power X25, a fixed distance $3 \mathrm{~mm}$ all over the socket walls facing the implant space was cut as a layer region of interest (ROI)\}, and placed in new plank picture. Then, selection of the color representing the level of mineralization, and calculating area $\%$, were done.

Statistical analysis was performed by software program SPSS, statistical package for social sciences, V 19.0 for Windows (SPSSINC, Chicago, USA). paired Wilcoxon test was uses for various non-parametric tests. Data were presented as mean and standard deviation (SD) values and the significant level was set at $\mathrm{P}<0.05$. 


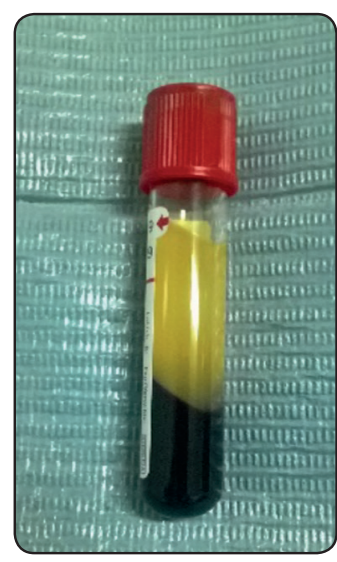

Fig. (1) PRF prepared

\section{RESULTS}

At one month, Group 1 (control) revealed numerous irregular thickness bony trabeculae with different patterns at the socket walls, enclosing numerous vascular marrow spaces. Group 2 (PRF) showed large sized and thick trabeculae with minimal and narrow marrow spaces.

At three months: Group 1 revealed the boney trabeculae appeared irregular with more fibrous tissues. Group2 revealed thick bone trabeculae

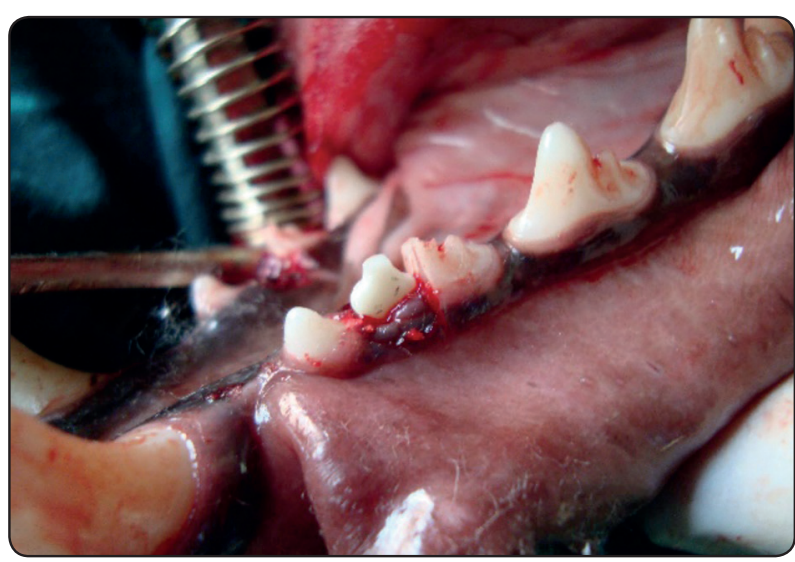

Fig. (2) Seating of implant

coalesced with each other enclosing narrow marrow spaces all over the socket walls.

Alizarin Red Stain: The image analysis was shown in table (1-3) and figure (3-7).

\section{Image analysis results of Alizarin Red Stain:} The calcified bone volume was expressed as a percentage of the calcified bone over the total region of interest $(\mathrm{ROI})$ volume using the equation: (Calcified Bone volume/total ROI tissue volume $\times 100)$

TABLE (1): Alizarin Red Calcified area \% values of both groups, at different time intervals:

\begin{tabular}{|c|c|c|c|c|c|c|}
\hline Time intervals & Slide1 & Slide2 & Slide3 & Slide4 & Slide5 & Mean \\
\hline 1month (group1) & 49.8 & 50 & 50.2 & 50.11 & 50.31 & 50.084 \\
\hline 1 month (group 2) & 50 & 49 & 51 & 50 & 50 & 50 \\
\hline 3 months (group 1) & 50.52 & 50 & 50.35 & 50.4 & 50.6 & 50.374 \\
\hline 3 months (group 2) & 66.51 & 55.92 & 66.1 & 66.4 & 66.3 & 64.246 \\
\hline
\end{tabular}

TABLE (2): Comparison between the alizarin red calcified area percent of group 1, and group 2, at different time intervals:

\begin{tabular}{|c|c|c|c|c|c|}
\hline Time intervals & Mean & SD & SE & $P$ value & Significance \\
\hline 1month (group1) & 50.084 & 0.19552 & \multirow[t]{2}{*}{0.372} & \multirow[t]{2}{*}{0.8278} & \multirow[t]{2}{*}{ Ns } \\
\hline 1 month (group2) & 50 & 0.63246 & & & \\
\hline 3months (group1) & 50.374 & 0.23104 & \multirow[t]{2}{*}{2.284} & \multirow[t]{2}{*}{0.0006} & \multirow[t]{2}{*}{$* * *$} \\
\hline 3 months (group2) & 64.246 & 4.65682 & & & \\
\hline
\end{tabular}




\begin{tabular}{|c|c|c|c|c|}
\hline & $\begin{array}{c}\text { Control group } \\
\text { (Alizarin Red stain X25) }\end{array}$ \\
One \\
month
\end{tabular}

Table (3): Comparison between the alizarin red calcified area percent of the same group by time:

\begin{tabular}{|l|c|c|c|c|}
\hline & & SE & P value & \\
\hline Group 1 & $3 \mathrm{~m}$ Vs 1m & 0.139 & 0.0419 & $*$ \\
\hline Group 2 & $3 \mathrm{~m}$ Vs 1m & 2.389 & 0.0006 & $* * *$ \\
\hline
\end{tabular}

Vs----versus, ${ }^{* * * *} p<0.001 ; * * p<0.01 ; * p<0.05 ; \mathrm{Ns}=$ nonsignificant.

Accordingly, at one-month, there was no statistical significant difference between the two groups. At 3 months, there was a high statistical significant difference between the two groups. At 3 months, there was a marked increase of calcification in comparison with one month on both groups. Also, there was a significant difference between the two groups at 3 months, which means that group2 showing more mineralization at the same time interval than that of group1.

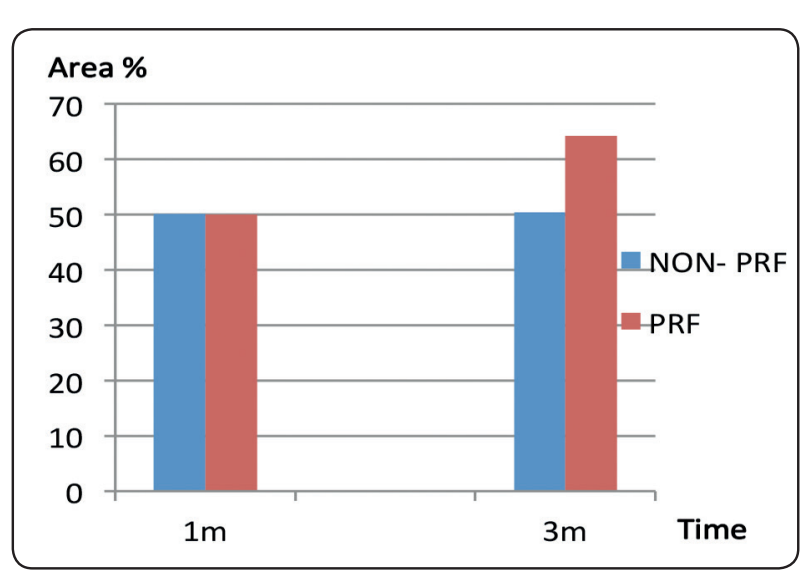

Fig. (7) Curve comparing effect of treatment by time in both groups (alizarin red stain). 


\section{DISCUSSION}

The advantages of immediate implant placement are the decrease in the treatment time for the patient, the reduction in the number of surgical interventions leading to an improved quality of life and cost reduction. Alveolar bone resorption and soft tissue regression are significantly reduced, due to early, albeit limited, functional load ${ }^{[10]}$. One problem associated with immediate implant placement using conventional screw-or cylinder-type implants is their Incongruence with the extraction socket necessitating the use of a barrier membrane and/or bone augmentation ${ }^{[11]}$.

Pirker and Kocher (2008) ${ }^{[12]}$ were the pioneers in studying Immediate, non-submerged; root-analogue zirconia implant in single tooth replacement. This case report demonstrates the successful clinical use of this technique. However, little information is available till now about enhancing osseointegration for such approach. The development of bioactive surgical additives, to regulate the inflammation and increase the speed of healing process ${ }^{[2]}$, such as platelets rich fibrin was considered in this study.

All the implants of both sides of the mandible were immobile, with apparent healthy peri-implant tissue and no peri-implant tissue infection. These results go in accordance with many earlier studies on dental implants ${ }^{[13-14]}$.

Osseointegration may be broadly defined as the dynamic interaction and direct contact of living bone with a biocompatible implant in the absence of an interposing soft tissue layer ${ }^{[15]}$, (histo-path ological definition).

PRF is a healing biomaterial with a great potential for bone and soft tissue regeneration, without inflammatory reactions promoting hemostasis, bone growth, and maturation. This autologous matrix demonstrated a great potential to increase cell attachment and a stimulation to proliferate and differentiate osteoblasts and maturation of bone enhancing Osseointegration. These results are matching with Dohan et al. ${ }^{[16]}$ who stated that PRF has immunological and antibacterial properties, may lead to leukocyte degranulation, and has some cytokines that may induce angiogenesis and pro/antiinflammatory reactions. Also matches with Öncü E et al ${ }^{[17]}$ who found in their study, PRF application increased implant stability during the early healing period, as evidenced by higher Implant Stability Quotient (ISQ) values. Simple application of this material seems to provide faster osseointegration

Some advantages of PRF are reported in many researches and noted during this study, such as: Its preparation is a simplified and efficient technique, with centrifugation in a single step ${ }^{[18]}$. It is obtained by autologous blood sample ${ }^{[19]}$. It does not require the addition of external thrombin because polymerization is a completely natural process, without any risk of suffering from an immunological reaction ${ }^{[2,20]}$. It has a natural fibrin framework with growth factors within that may keep their activity for a relatively longer period and stimulate tissue regeneration effectively ${ }^{[21]}$. It can be used solely or in combination with bone grafts, depending on the purpose ${ }^{[18]}$. But PRF may present some disadvantages as follows: The final amount available is low because it is autologous blood. Need of using a glass or glass coated tube to achieve clot polymerization ${ }^{[19]}$.

In this study, PRF enhanced fast healing process and mineralization by time than the control group.

\section{CONCLUSION}

PRF has demonstrated safe and promising results. Zirconia root analogue dental implants with PRF showed a higher percentage of bone formation which is an indicator of their Faster and better osseointegration 


\section{REFERENCES}

1. Amod Patankar, Rajesh Kshirsagar, Swapna Patankar and Sudhir Pawar. Immediate, Non-Submerged Root Analog Zirconia Implant in Single Rooted Tooth Replacement: Case Report with 2 years Follow Up. J. Maxillofac. Oral Surg. 2016;15: 270-273.

2. Dohan DM1, Choukroun J, Diss A, Dohan SL, Dohan AJ, et al. Platelet-rich fibrin (PRF): a second-generation platelet concentrate. Part I: technological concepts and evolution. Oral Surg Oral Med Oral Pathol Oral Radiol Endod 2006; 101: e37-44.

3. Singer AJ and Clark RA. Cutaneous wound healing. N Engl J Med 1999; 341: 738-746.

4. Gassling VL, Açil Y, Springer IN, Hubert N and Wiltfang J. Platelet-rich plasma and platelet-rich fibrin in human cell culture. Oral Surg Oral Med Oral Pathol Oral Radiol Endod 2009; 108: 48-55.

5. Ross R, Glomset J, Kariya B and Harker L. A plateletdependent serum factor that stimulates the proliferation of arterial smooth muscle cells in vitro. Proc Natl Acad Sci U S A 1974; 71: 1207-1210.

6. Kiran NK, Mukunda KS and Tilak Raj TN. Platelet concentrates: A promising innovation in dentistry. J Dent Sci Res 2011; 2: 50-61.

7. Whitmann DH, Berry RL and Green DM. Platelet gel: an alternative to fibrin glue with applications in oral and maxillofacial surgery. J Oral Maxillofac Surg 1997; 55: 12941299.

8. Choukroun J, Adda F, Schoeffler C and Vervelle A. Une opportunité en paro-implantologie: le PRF. Implantodontie 2000; 42: 55-62.

9. Fawad Javed, Hameeda Bashir Ahmed, Roberto Crespi, and Georgios E. Romanos. Role of primary stability for successful osseointegration of dental implants: Factors of influence and evaluation. Interv Med Appl Sci. 2013 Dec; 5(4): 162-167.

10. Becker W, Becker BE, Handelsman M, Ochsenbein C, Albrektsson T. Guided tissue regeneration for implants placed into extraction sockets: A study in dogs. Journal of Periodontology. 1991; 62: 703-709.

11. Allen C. Curious observations on the teeth. John Bale, Sons \& Danielsson, LTD 1987: pp.12-13.
12. PirkerW, KocherA: Immediate, non-submerged, root-analogue zirconia implant in single tooth replacement. Int. J. Oral Maxillofac. Surg. 2008; 37: 293-295.

13. Andersson B, Ödman P, Lindvall A-M, Brånemark P-I: Five-year prospective study of prosth-odontic and surgical single-tooth implant treatment in general practices and at a specialist clinic. Int J Prosthodont. 1998; 11: 351-355.

14. Schulte W: The intra-osseous Al2O3 (Frialit) Tuebigen Implant. Developmental status after six years. Zahnärztl Mitt. 1981; 71: 1181-9215.

15. Brånemark P-I: Introduction to osseointegration. In: Brånemark P-I, Zarb G, Albrektsson T, (eds). Tissue integrated prostheses - osseointegration in clinical dentistry. Quintessence, Chicago, pp 11-76 (1985).

16. Dohan Ehrenfest DM, Del Corso M, Diss A, Mouhyi J and Charrier JB. Three-dimensional architecture and cell composition of a choukroun's platelet-rich fibrin clot and membrane. J Periodontol 2010; 81: 546-555.

17. Öncü E, Alaaddinoğlu EE. The effect of platelet-rich fibrin on implant stability. Int J Oral Maxillofac Implants. 2015; 30: $578-582$.

18. Simonpieri A, Del Corso M, Vervelle A, Jimbo R, Inchingolo F, et al. Current knowledge and perspectives for the use of platelet-rich plasma (PRP) and platelet-rich fibrin (PRF) in oral and maxillofacial surgery part 2: Bone graft, implant and reconstructive surgery. Curr Pharm Biotechnol 2012; 13: 1231-1256.

19. Choukroun J, Diss A, Simonpieri A, Girard MO, Schoeffler C, et al. Platelet-rich fibrin (PRF): a second-generation platelet concentrate. Part IV: clinical effects on tissue healing. Oral Surg Oral Med Oral Pathol Oral Radiol Endod 2006; 101: e56-60.

20. Kang YH, Jeon SH, Park JY, Chung JH, Choung YH, et al. Platelet-rich fibrin is a Bioscaffold and reservoir of growth factors for tissue regeneration. Tissue Eng Part A 2011; 17: 349-359.

21. Wu CL, Lee SS, Tsai CH, Lu KH, Zhao JH et al. Platelet-rich fibrin increases cell attachment, proliferation and collagen-related protein expression of human osteoblasts. Aust Dent J 2012; 57: 207-212. 